\title{
The Complex System in Babel
}

\author{
Liliek Soelistyo, Dwi Setiawan \\ English Department, Faculty of Letters, Petra Christian University \\ Siwalankerto 121-131, Surabaya 60236, East Java, Indonesia \\ e-mail: 1syuwono@peter.petra.ac.id; dewey@peter.petra.ac.id
}

\begin{abstract}
This article discusses how the plot of Babel reflects the principles of the quantum-physic theory of complex system such as complexity, indeterminacy and non-linearity. In terms of complexity, the movie exposes more than two distinct subplots with their subcomponents. Yet, every subplot is only meaningful when it is mentally put in relation to the others. Due to its complexity, it is highly difficult for the audience and the characters of Babel to determine the meaning or the significance of a component in the story. Finally, Babel also displays the phenomena of non-linearity and chaos. Babel's non-linearity expresses both positive and negative feedback loops, with the first being dominant. This is largely responsible for the chaotic development of the plot.
\end{abstract}

Key words: complex system, complexity, indeterminacy, nonlinearity (chaos)

According to Chatman taxonomy, film, like drama, is listed both as a performed and a narrative genre (as cited in Manfred 2003). Film is realized in the framework of a presentation as well as a textual form (a script). Since it is assumed that film is a narrative form, plot is applicable to film, too. Text can have widely differing degrees of plot connectivity (Manfred, 2003). Some are tightly plotted or have 'linear plots' where everything ties in with everything else in orderly sequence. Others have mosaic plots, i.e., they are loosely plotted, episodic, accident driven and possibly avoid causal plotting altogether. Mosaic-plotted films are getting popular these days and are also known as 'hyperlink cinema'. This term is coined by author Alissa Quart, who used the term in her review for the film journal Film Comment in 2005. Ebert (2005) describes hyperlink cinema as films where the characters or actions reside in separate stories, but a connection or influence between those separate stories is slowly revealed to the audience. It is illustrated in Don Roos' Happy Ending (2005), Stephen 
Gagan's Syrana (2005), and Alejandro González Iñárritu's Amores Perros (2000), 21 Grams (2003), and Babel (2006).

Out of all hyperlink movies by Innaritu and others, Babel deserves a special attention due to its level of complexity and its balance presentation. This Golden Globe-and Academy Award-winning 2006 film weaves together four interrelated sets of situations and characters. In some hyperlink cinemas, the interlocking stories spun a little out of control. Everything finally fits together but there is sometimes the sense that the audience is more disoriented than the films really wanted it to be. In some others, however, the interrelated stories are either too easy to follow or superficially made. In Babel, Ebert (2005) finds Inarritu in full command of the technique. The script writing and the movie editing move between the stories with full logical and emotional clarity.

The plot starts in a remote desert location in Morocco, where Abdullah, a goat herder, buys a rifle from his neighbor Hassan to tend his goats. Abdullah gives the rifle to his two teenage sons, Yussef and Ahmed, and sends them out to the herd. Doubting the rifle's purported 3-km range, the kids decide to test it out to a bus carrying Western tourists. Yussef's bullet hits Susan Jones, an American woman traveling with her husband Richard Jones. Due to the incident, their nanny, Amelia, is forced to take care of their children in California longer than anticipated. Unable to miss her son's wedding in Mexico, Amelia decides to take the children with her nephew, Santiago, as the driver. When they return to the States, Santiago has been drinking heavily, trespasses the border, and abandons Amelia and the children in the desert. Amelia has to leave the children behind to find help and meets a U.S. Border Patrol officer. The children are found but Amelia is deported from the US due to her illegal-immigrant status. Simultaneously, the movie tells the story of Chieko, a rebellious, deaf Japanese teenage girl. She is bitter towards her father, Yasujiro, and is sexually frustrated. One day Chieko meets an attractive detective. Thinking that the detective is investigating her mother's suicide, she explains that her father is innocent and that she witnessed the suicide herself. It turns out the detective is investigating a hunting trip Yasujiro took in Morocco. During his trip, he gave his rifle as a gift to his hunting guide Hassan, and this gesture triggers other series of events, indicating the complexity of the interconnection of the subplots.

This article aims to expose the complex system in Babel's plot. In particular, the writers wish to show how the plot reflects the principles of 
the quantum physic theory of complex system such as complexity, indeterminacy and non-linearity. Etymologically, 'complexity' comes from the Latin word complexus, which means 'entwined' or 'embraced' (Heylighen \& Gershenson, 2004). It implies that in order to have a complex a system needs 1) two or more distinct parts 2) that are joined in such a way that it is difficult to separate them. Here one finds the basic duality between parts which are at the same time 'distinct' and 'connected'. According to Heylighen and Gershenson (2004), the complexity of a system increases with the number of distinct components, the number of connections between them, the complexities of the components and the complexities of the connections. The components are mutually entangled, so that a change in one component will propagate through a tissue of interactions to other components that in turn will affect even further components, including the one that initially starts the process. This makes the dynamics of the system very hard to track in terms of its elements.

Indeterminacy means that "a distinction made by one observer in one context may no longer be meaningful or even possible for another observer in another context" (para. 8). A good example of this is the well-known ambiguous figure that contains the pictures of both an old and a young woman:

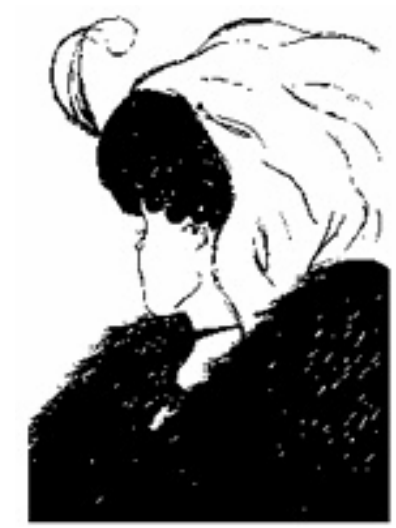

While both 'pictures' are equally existent in the figure, our limited perception does not allow us to see them at the same time, and thus we tend to switch back and forth between the two pictures. The two pictures are complementary, meaning they are distinct, yet joined together. With a simple system as such, the number of pictures is limited. However, a more 
complex system has many different types of pictures and connections that it may appear impossible to recognize them as parts of the same thing.

Furthermore, a complex system embodies the principle of nonlinearity. A system is linear if effects (outputs) are dependent on their causes (inputs). For example, if one invests twice as much capital to his/her shop, it will produce roughly twice as much profit. In a complex system, however, the interdependencies are such that the inputs will affect the outputs, but the outputs will in general also affect the inputs. Back to the previous example, the system becomes complex if it involves the shop owner reinvesting (part of) the profit to the shop. So, the investment determines the profit but the profit equally affects the (next) investment. The bigger the investment is, the bigger the profit. The bigger the profit is, the bigger the investment. Complex systems are characterized by networks of such non-linear loops.

The result is that "the tiniest, microscopic difference between the initial states can grow into macroscopically observable distinction" (para. 17). When (part of) the profit is reinvested to increase production, conceptually the next output will be larger, since it uses both the input and the previous output, and therefore no longer proportional to the input alone. The next output will be even larger, as it uses not only the new input but also the two previous outputs. Because the initial difference is too small to perceive, the principle of causality cannot help one in predicting the final outcome. The growth of the situation depends on the effects of the feedback such as 'positive' or 'negative' (para. 17). The effect of a positive feedback loop is not necessarily 'positive' in the sense of being desirable. The name refers to the nature of change rather than the desirability of the outcome. A negative feedback will counteract or resist any variation in the input, bringing the system to its equilibrium state. Thus, large causes may have little or no effect. On the other hand, a positive feedback will amplify any variation in the input, making it grow exponentially. Similarly, small causes can have large effects that in the Complexity Theory are called as the 'Butterfly Effects' (para. 18).

\section{BABEL'S COMPLEXITY}

As a system, Babel exhibits a high degree of complexity in terms of its components and connections. First of all, Babel has more than two distinct components and even sub-components. The film weaves together subplots 
taking place in Morocco, the US, Mexico, and Japan. Each subplot has its own distinct characters, events/actions and setting. Every character acts in his/her own setting. The Moroccan boys, Ahmed and Yussef, only appear in Morocco, although their exploit reach the other side of the world. Yasujiro, the Japanese father, never appears in Morocco although it is told that he had been there. Thus, every character starts, acts and ends in his/her typical setting.

Inside these subplots, there are still some distinct subcategories. For instance, the subplot in Morocco tells two distinct stories. The first is about the Moroccan boys/the culprits and the second the American woman (Susan)/the victim. Each subplot also involves a number of typical characters. For example, in the Japanese subplot, one has the Japanese girl, her friends, her father and the detective. The characters in that subplot have various professions such as students, punks, a businessman and a policeman. Furthermore, each subplot also has more than one distinct setting. The story of the Mexican nanny incorporates two different settings such as USA and Mexico.

However, those distinct elements and sub-elements are only meaningful when it is mentally put in relation to the others. One will not possibly understand why the police torture Hasan, the guide, hunt down the boys and even kill one of them if $\mathrm{s} / \mathrm{he}$ is given a chance to see only one subplot and not the others. Similarly, one might not be able to understand the emotional scene of the American couple, Susan and Richard, if $\mathrm{s} /$ he is not given a picture of the two children they have left in the States. Every component is joined in such a meaningful way that it is difficult to separate them.

Furthermore, every character is closely related to another character inside and outside his/her subplot. Inside her own subplot, the existence of Susan as a character could not be separated from the character of the Moroccan boys and the police. One might not understand the significance of the Nanny as a character if s/he does not grasp the Nanny's relation to Susan and Richard back in Morocco. One might also be wondering why the film presents Chieko, the sexually frustrated, deaf Japanese girl, as a character if s/he does not see her relation to Hasan and the Moroccan boys.

Similarly, every action depends much on another action both in and out its subplot. In its own subplot, the shooting by the boys leads to their escape and their being hunted. Similarly, the Nanny's action of bringing the children to Mexico leads to her being deported to the country. 
Outwardly, the significance of the shooting in Morocco lies on the fact that it is able to trigger reactions in other subplots e.g., the nanny bringing the children to Mexico, the pressure from the U.S government to its Moroccan counterpart, the investigation toward Chieko's father. Thus, not only does Babel involve a big number of different components and subcomponents, but it also incorporates a numerous, highly complex interconnection between the components.

\section{BABEL'S INDETERMINACY}

The complexity of Babel leads one to the movie's next interesting feature: indeterminacy. Due to the high number of the components and connections, it is highly difficult for the audience to determine the meaning or the significance of a component or a subcomponent in the movie. As the audience is watching the two Moroccan brothers doubt the rifle's purported three-kilometer range and test it out, it finds it difficult to figure out its meaning. Nobody guesses that such a gunshot can change lives across the globe. Similarly, the audience cannot accurately determine the significance of the Mexican nanny as she appears on the screen. The more confusion comes when it watches the character and the action of Chieko at the beginning of the subplot. In short, the audience finds it just difficult to recognize all those different components in the movie as parts of the same story

The indeterminacy is doubled when the audience realizes that there is no way to understand a component without dismissing and then recalling it back and forth. Most of the time, the meaning of a component is just revealed when the audience is watching another component. For instance, the significance of the Nanny is just revealed when the audience is watching Richard making a phone call. Likewise, the audience begins to see the significance of the shooting when they are watching Susan being hit. However, as they try to clarify this guess, their mind has to go back to the shooting scene and, consequently, must dismiss the Susan's scene. In other words, they realize the significance of the shooting at the expense of their understanding of Susan. With this sort of understanding process, the audience is in constant confusion throughout the movie.

The difficulty in seeing and understanding the meaning of a component is also experienced by the characters, thanks to their different settings and their ignorance of the complexity of the system. The Japanese 
father does not see and understand the outcomes of his souvenir giving simply because he is in Japan and is innocent that his good action can create such an ugly result. Due to their escape from the crime scene and innocence of world's politic, the Moroccan children does not see and understand the impacts of their exploits to the other characters and themselves. Because of precisely the same things, Richard and Susan cannot see their assailants and predict their fate. The American couple does not see and understand the outcome of the delay to the Nanny and the children either as they are not in Mexico or are innocent of the Nanny's dilemma. The best that the characters can perceive and understand is those which happen to be in their own setting/context.

\section{$B A B E L ' S$ NON-LINEARITY AND CHAOS}

As a complex system, Babel also displays the phenomena of nonlinearity and chaos. First of all, the plot of Babel is typified by non-linear relations of the components. In Babel, the latter conditions affect the initial as much as the initial do the latter. For the sake of example, one may take the first initial condition as when the Moroccan boys doubts the $3 \mathrm{~km}$ purported range of the gun and innocently tests it out by aiming at the bus of western tourists. The impact of this action is the bullet hits Susan and the bus stops. Being aware of the possible outcome of their exploit, the boys fly away from the scene. Here, the boys' action (the cause) endangers the American woman (the impact) but the woman's situation scares the boys (the cause) away. Another example of the non-linear loop occurs in the interaction between the American couple and the Nanny. As the couple asks the Nanny to take care of their children longer than anticipated, the Nanny has to risk the well being of the children and thus worries the couple. The couple's action (the cause) puts the Nanny into trouble (the impact) but the Nanny's trouble (the impact) in turn distresses the couple (the cause).

Furthermore, Babel's non-linear causal order expresses both positive and negative feedback loops. As in the case of the Moroccan boys and the American couple, the feedback from the couple to the boys is positive, in the sense that it produces a variation in the initial situation of the boys. In the first initial condition, the boys are innocent and careless. In the second, they are guilty and, in ironic sense of course, wise. Whenever a character gives a positive feedback, the number of connected components is getting 
bigger and the problem is becoming more complex. For instance, the involvement of the U.S. government in this matter is the result of the positive feedback given by the boys to Susan. As can be seen in the following analysis, the problem indeed gets worse when they get involved. In contrast, what the Nanny gives to the American couple is a negative feedback. It may distress the couple but it does not change its loving attitude toward the Nanny. As the couple decides not to sue the Nanny, the number and tension stop, and the story meets its end. Here any variation is counteracted or resisted, bringing the system to its equilibrium state.

As a matter of fact, the number of positive feedbacks in Babel is way above the negative. This is what makes the plot develop exponentially and unpredictably. Such a simple and tiny change as in the initial condition of the boys is responsible for the chaotic and huge outcomes in the plot. Alphabet is assigned to the characters to demonstrate how the positive feedbacks absorb new interested parties into the problem and, therefore, make the matter worse. As the boys (A) run away, Susan (B) has no idea who shoots her. This situation provokes the involvement of a new party, the U.S. government $(\mathrm{C})$ as it speculates about a deliberate terrorist attack. In turn, the superpower government presses its weak Moroccan counterpart (D) to carry out an investigation. A new party has been brought into the problem.

The newly-involved Moroccan police (D) then look for the culprits and eventually find out that they are Yussef and Ahmed (A). The children (A) open fire when the police (D) push them to a hill. This is another positive feedback as it changes the boys' status from being harmless to being hostile. As a result, the police get infuriated and shoot Ahmed on his leg. Yussef, knowing this, returns fire and wounds one police officer. The police continue shooting, and Ahmed dies in the battle, while Yussef surrenders and is brought to jail. In the above fragment, one can also see how the initial cause, the boys (A), is affected by one of its long-due outcomes, the Moroccan police (D).

Based on the feedback given by the Moroccan government (D), the U.S. government (C) asks the Japanese government (E) to clarify the result of the investigation. The feedback from the Moroccan government is positive because it changes the initial assumption of the U.S. government about the terrorist threat. However, as it were, that positive feedback draws another party into the scene, the Japanese government (E). In turn, the Japanese government (D) carries out an investigation, and it affects the life 
of Yasujiro and Chieko (E). It is found out that Yasujiro has once had a hunting trip to Morocco and is guided by a tour guide, Hassan. As gratitude, Yasujiro gives his rifle to Hassan who then sells it to Abdullah, the father of the two Moroccan boys, Yussef and Ahmed. Knowing this, one may now wonder whether Yasujiro is the ultimate victim or the initial cause; whether he is character E or character A. Indeed, in a sophisticatedly non-linear environment as in Babel's plot, it is not easy to tell who initiates the initial action that triggers the exponential and unpredictable development of the plot.

\section{CONCLUSION}

In conclusion, Babel reflects the qualities of a complex system. As a system, it exhibits a high degree of complexity in terms of its components and connections. Babel has more than two distinct subplots and even subcategories. Yet, each of them is meaningful only when it is mentally put in relation to the others. Furthermore, the movie displays another feature of a complex system: indeterminacy. It is highly difficult for the audience to determine the meaning or the significance of a component or a subcomponent in the movie. This difficulty is doubled when the audience realizes that there is no way to understand a component without dismissing and then recalling it back and forth. The best that the characters can perceive and understand is those which happen to be in their own setting/context. Babel also displays the phenomena of non-linearity and chaos. Babel's non-linearity expresses both positive and negative feedback loops, with the first being dominant. This is what makes the plot develop exponentially and unpredictably. Indeed, in such a non-linear environment as in Babel's plot, it is not easy to tell who initiates the initial action. This article is an attempt to facilitate the dynamic interface of what so-called 'science' and 'humanities'. As implied from the analysis, a theory of science can help to understand and even to appreciate an artifact of humanities.

\section{REFERENCES}

Ebert, R. (2007). Babel (2006). Retrieved July 28, 2007, from http://rogerebert.suntimes.com/apps/pbcs.dll/article?AID=/20070922/REVIEWS08/709 22001/1023 
Heylighen, F., \& Gershenson, C. (2004). How can we think complex? Retrieved July, 2006, from http://www.vub.ac.be/CLEA.

Manfred, J. (2003). Poems, plays, and prose: A guide to the theory of literary genre. Retrieved May 8, 2007, from http://www.uni-koeln.de/ ame02/ ppp.htm

Quart, A. (2005). Networked. Film Comment, 41(4), 45-8.

Zukav, G. (1978). The dancing Wu Li masters: An overview of the new physics. The British Channel Islands: The Guernsey Press. 